\title{
"PLEASE SEND US A PRIEST OF OUR GERMAN NATIONALITY...”: THE CONFESSIONAL/ETHNIC IN THE WORLDVIEW OF THE SIBERIAN CATHOLICS
}

\section{Tatyana G. Nedzelyuk}

Siberian Institute of Management - Branch of the Russian Presidential Academy of National Economy and Public Administration. Nowosybirsk, Russia. Email: tatned[at]mail.ru

\begin{abstract}
The study is devoted to the analysis of the correlation of the confessional element with the ethnic element within the construction of "ethnoconfession" for the Catholic Germans of Siberia. The relevance of the study of the topic is dictated by the modern processes of ethnic and confessional identification/self-identification that have replaced globalization. Notably, due to the multi-ethnic and multi-confessional nature of the Siberian population, a peculiar and unique concept of the frontier has developed, determined by historians as the "Siberian frontier". The temporal boundaries of the study include the twentieth century: from the moment of mass migrations from the Crimea, the Volga region and Ukraine to the Trans-Urals in the context of the Stolypin agrarian reform to the beginning of the active return movement of Russian Germans to Germany. The methodological basis of the study was the work of both ethnographers and sociologists. The content analysis method revealed the peculiarities of the mentality of representatives of various confessional groups within the German ethnic group. The research is based on the materials of the Russian State Historical Archive. The conclusions about the importance of confessional self-awareness are important for the self-identification and successful socialization of Russian Germans. The article is intended for specialists in the field of history and ethnography of Russian Germans, as well as for researchers interested in the features of frontier communications in Siberia.
\end{abstract}

\section{Keywords}

Siberian Frontier; Ethno-Confession; Methodological Discourse; German Ethnos; Siberian Catholics; Confessional Identity; Ethnic Identity; National Identity; Polyconfessional; Frontier Ethno-Confessionalism of the Germans in Siberia

This work is licensed under a Creative Commons «Attribution» 4.0 International License 


\title{
«ПРОСИМ ПРИСЛАТЬ НАМ СВЯЩЕННИКА НАШЕЙ НЕМЕЦКОЙ НАЦИОНАЛЬНОСТИ...»: КОНФЕССИОНАЛЬНОЕ / ЭТНИЧЕСКОЕ В КАРТИНЕ МИРА КАТОЛИКОВ СИБИРИ
}

\begin{abstract}
Недзелюк Татьяна Геннадьевна
Сибирский институт управления - филиал Российской академии народного хозяйства и государственной службы при Президенте Российской Федерации. Новосибирск, Россия. Email: tatned[at]mail.ru
\end{abstract}

\section{Аннотация}

Исследование посвящено определению соотношения конфессионального элемента с этническим внутри конструкции «этноконфессия» для немцевкатоликов Сибири. Актуальность изучения темы продиктована современными процессами этнической и конфессиональной идентификации / самоидентификации, пришедшими на смену глобализации. Характерно, что в силу многонациональности и поликонфессиональности сибирского населения сложился своеобразный и уникальный концепт фронтира, детерминируемый историками как «сибирский фронтир». Темпоральные границы исследования включают XX столетие: от момента массовых переселений из Крыма, Поволжья и Украины в Зауралье в контексте Столыпинской аграрной реформы до начала активного возвратного движения российских немцев в Германию. Методологическим базисом исследования выступили работы как этнографов, так и социологов. Метод контент-анализа позволил выявить особенности менталитета представителей различных конфессиональных групп внутри немецкого этноса. Источниковая основа исследования базируется на материалах фонда Канцелярии митрополита римско-католических церквей в России в составе Российского государственного исторического архива. Выводы о значимости конфессионального самосознания важны для самоидентификации и успешной социализации российских немцев. Статья рассчитана на специалистов в области истории и этнографии российских немцев, а также исследователей, интересующихся особенностями фронтирных коммуникаций в Сибири.

\section{Ключевые слова}

сибирский фронтир; этноконфессия; методологический дискурс; немецкий этнос; сибирские католики; конфессиональная идентичность; этническая идентичность; национальная идентичность; поликонфессиональность; фронтирная этноконфессиональность немцев в Сибири

Это произведение доступно по лицензии Creative Commons «Attribution» («Атрибуция») 4.0 Всемирная 


\section{ВВЕДЕНИЕ}

В массовом сознании существует устоявшееся, стабильное представление об этноконфессии: русские отождествляются с православием, поляки - с католицизмом, индусы - с буддизмом и т.д. Немецкий этнос на протяжении последних шести столетий после Реформации, инициированной Лютером, демонстрирует иную модель этноконфессиональности. Немцы - поликонфессиональны. Мало того, что их конфессиональность вариативна; стоит также поговорить о степени соотнесенности конфессионального элемента с этническим внутри конструкции «этноконфессия».

Ситуация фронтира не уничтожает и не нивелирует этот вопрос, напротив - делает лишь более рельефным, значимым и ярко демонстрирует значимость не только конфессиональных различий, но и этнического единства.

Итак, целью настоящей статьи является изучение феномена соотносительности (соотнесенности) конфессионального и этнического компонентов внутри той части немецкого этноса, которая во второй половине XIX-XX вв. оказалась вовлеченной в сибирский социум и включенной в ситуацию «сибирского фронтира».

\section{МЕТОДОЛОГИЧЕСКИЕ ОСНОВЫ ИССЛЕДОВАНИЯ}

Несмотря на кажущуюся очевидность, содержательная наполненность концептов «конфессиональная идентичность» и «этническая идентичность» не является окончательно и исчерпывающе определенной. Недавняя публикация в журнале «Религиоведение» результатов совместного исследования социологов И. А. Юрасова и О. Н. Юрасовой наглядно демонстрирует незавершенность методологического дискурса (Юрасов \& Юрасова, 2020, сс. 108-118).

Так, авторы дифференцируют понятия «конфессиональная идентичность» и «религиозная идентичность», но не дают пояснений относительно этнической и национальной идентичностей, употребляя эти термины в качестве синонимичных конструкций (с. 108). В исследовании презюмируется, что «религиозная и конфессиональная идентичности являются также и признаками национальной идентичности» (с. 110). Таким образом, национальная идентичность позиционируется концептом более широкого значения. Как видим, тематика конфессионального/этнического дискурсов находится в полидисциплинарном научном поле.

Мы вполне согласны с утверждением социологов о том, что: 
«В процессе социализации индивид осваивает родной язык, интериоризирует через бытовую культуру национальные ценности, основанные на обычаях, традициях и народной культуре».

На основании ценностей языка и народной культуры при наличии системы религиозных чувств и навыков, которые получили название «религиозный интеллект», происходит формирование конфессиональной идентичности» (с. 114).

Мы поддерживаем утверждения этих, и не только, авторов (Beliakova \& Dobson, 2016; Белякова \& Микешин, 2018; Герман, 2019; Беглов, Токарева \& Фадеев, 2020) о религиозной идентичности как об интериоризации свих убеждений и своего поведениями с теологическими установками, а конфессиональной идентичности - как соотнесенности с типом конкретного религиозного сообщества, но не разделяем убежденности в том, что:

«...конфессиональная идентичность является проекцией национальной, этнической идентичности» (Юрасов \& Юрасова, 2020, с. 108).

\section{ОСНОВНАЯ ЧАСТЬ}

Исследовательница теории фронтира Д.С. Панарина указывает, что в понимании европейцев фронтир «представлял собой границу, противопоставляющую и разъединяющую две социальные, политические или культурные протяженности» (Панарина, 2015, с. 18). Граница с новоосваиваемыми территориями - американская версия теории фронтира. По мнению авторов «фронтирной концепции», в том числе американского историка Дж. Форбса, принципиальное значение имеет «точка встречи, где две силы сталкиваются друг с другом, будь то группы людей» или достаточно абстрагированные концепты, которые Форбс именует «цивилизацией» и «дикой местностью» (Форбс, 1968, c. 206). Ряд важных выводов относительно проблем, подстерегающих мигрантов, сделала О.А. Лиценбергер (2014, сс. 70-78).

Широкое, территориально ориентированное значение, подразумевающее «не только отграничительную линию, а область взаимодействия и взаимовлияния народов, её населяющих», - русский вариант трактовки теории фронтира (Ремнев, 2015). Не случайно рядом авторов (Резун \& Шиловский, 2005; Ремнев, 2011, 2015) введено в научный оборот понятие «сибирский фронтир». Д.Я. Резун и М.В. Шиловский подчеркивают, что сибирский регион подвергся не завоеванию, а хозяйственной и культурной ассимиляции (Резун \& Шиловский, 2005). 
Предлагаем рассмотреть разные грани «фронтирной этноконфессиональности» немцев в Сибири.

\section{Семья, брак, традиции воспитания детей}

Концепция идеального конфессионального брака предполагала брачный союз между адептами одной конфессии. Области, где компактно проживали переселенцы из западных губерний, составляли своеобразные круги брачных связей. В качестве примера рассмотрим опубликованные полевые данные этнографической экспедиции сотрудников Омского государственного университета в немецкие села (Смирнова, 2003). В ходе экспедиции было выявлено, что в деревне Чучкино Омской области: «браки, преимущественно однонациональные, заключались преимущественно внутри деревни, к чужакам относились настороженно. Дети поддерживали в чистоте веру своих предков. Родители могли сами выбрать невесту своему сыну, во всяком случае, их согласие было обязательным» (с. 20). Отметим, что деревню Чучкино населяли немцы католического вероисповедания. То же правило «работало» и у сибирских немцевлютеран. Участниками экспедиции в немецкие села отмечена важная закономерность:

«Хотя взаимоотношения жителей Красноармейки (Алтайский край) с представителями других конфессий были мирными, заключать браки предпочитали с лютеранами... в основном с жителями дер. Новоромановка» (с. 9).

Замкнутый конфессиональный социум представлял немного возможностей выбора, к тому же брачные союзы между хотя и дальними, но родственниками, критически отражались на здоровье потомства (первыми это заметили меннониты, создававшие общества призрения и благотворительной помощи для ментально больных и людей с нарушением слуха).

Экстраординарные случаи были редки, но имели место. Рассмотрим достаточно экзотический, но яркий пример: омские этнографы выявили случай межконфессионального взаимодействия в селе Сереброполье Алтайского края, когда браки заключались между лютеранами и меннонитами и назывались «божьими свадьбами» (c. 13).

Если в ближайшем единоверном окружении брачную пару по какой-то причине найти не удавалось, то предпринимались «выезды», возможно далекие, вплоть до поездок в материнские колонии Поволжья и Украины. Вот один из случаев: 
«Немец, по фамилии Нейфельд, родом из Солнцевки. Он приехал на Украину, где родились его родители, чтобы найти себе жену. В Солнцевке (Исилькульский район Омской области) за него замуж идти никто не хотел, потому что все знали, что он пьяница» (с. 22).

В качестве исключения, если не было возможности вступить в брак с единоверцем, практиковались брачные союзы с русскими, с православными. Объяснительных мотивов два. Первый: католикам брак с протестантами запрещен каноническим правом, закрепленным в традициях предков. Брак с православными не страшен, так как православие - тоже ортодоксальная религия. Мотив второй: русские титульная нация, и такой брачный союз может в перспективе повлечь повышение социального статуса.

Воспитание детей в конфессиональных традициях представляло собой неотъемлемую часть повседневного бытования немецкой семьи. Эмоции и впечатления, полученные в детстве, сопровождают человека всю жизнь, во многом определяя психологическое благополучие и вектор системы ценностей. Конфессиональная социализация детей в немецких семьях начиналась буквально с момента рождения (крещения). Обучение молитвенным практикам, стереотипам поведения являлось неотъемлемым элементом воспитания; поколенческий дискурс «запечатывался» семьей, общиной, конфессиональным приходом.

В исследовании, опубликованном по материалам всероссийского опроса С. В. Курске и Т. Б. Смирновой, отмечается: «подавляющее большинство респондентов считает, что национальность ребенка зависит от национальности родителей, главным образом - отца» (Курске \& Смирнова, 2011). Яркие впечатления информантов о применявшихся к детям наказаниях демонстрируют разность подходов к воспитанию. «Телесных наказаний меннониты не применяли. Напротив, лютеране или католики могли побить своих детей прутом или вожжами. Но внушение отца, наказание словом оказывалось ещё страшнее. К родителям обращались на «Вы». Днем все работали, а вечером по традиции вся семья собиралась за ужином. Отец читал молитву, только после этого разрешалось приступать к еде» (Смирнова, 2003, с. 28).

\section{Хозяйственный уклад, система землепользования}

Представители разных конфессий немецкого этноса образовывали, как правило, самостоятельные и независимые друг от друга поселения, что допускает их сравнение. 
Материалы переписей населения, сборники статистических сведений, информационные справки из «Списков населенных мест» Томской губернии (Сборник, 1912, 1913) дают основание сделать вывод о том, что лютеране проживали в селах Подсосново и Пришиб, Новенькое и Кругленькое. Католиками были населены Отрадное, Ольгино и Барское. Редкий пример смешанного в конфессиональном плане поселения представляла собой Редкая Дубрава. Материалы полевых исследований, опубликованные научно-исследовательской лабораторией этнографии и истории немцев Сибири при Омском государственном университете, сообщают:

«...в селе, основанном меннонитами, переселившимися с Украины, жили и католики, но на отдельной улице» (Смирнова, 2003, с. 11).

Из материалов этой же экспедиции становится ясно, что: «Шумановка была основана в 1911 г. украинскими меннонитами. По соседству находилось немецкое село Константиновка ${ }^{1} \ldots$ Несмотря на близкое соседство, шумановцы и циммертальцы практически не общались, а больше общались со своими единоверцами, даже из очень отдаленных деревень» (сс. 11-12).

Составителями сборника «Азиатская Россия» отмечено, что: «Не год, не два новоселы, особенно когда они селятся однородными по месту выхода группами в общих селениях или волостях, сохраняют природные особенности своего характера и все черты устройства своего на родине» (Азиатская Россия, 1914, с. 189). По мнению известного исследователя П. П. Вибе, «Сибирь была страной, где они надеялись спастись от малоземелья и нищеты» (Вибе, 2017, с. 14).

Директор Омского краеведческого музея П. П. Вибе отмечает безусловную практичность меннонитов и детерминирует причины успешности в хозяйственной сфере «корпоративностью, проявлявшейся в ярко выраженной склонности к взаимовыручке» (с. 19).

Главной причиной активного миграционного движения немцев из густонаселенных южных и западных губерний империи в Сибирь являлось льготное наделение землей. В сибирской землеустроительной практике сложились два варианта наделения новоселов земельными угодьями: подушевой (от 1 до 15 десятин на каждого мужчину в семье) и посемейный (60 либо 80 десятин земли на семью).

Вне зависимости от конфессиональной принадлежности, этнические немцы реализовывали схожий сценарий переселения на новые земли, детально описанный потомками меннонитов-переселенцев

1 Село Константиновка имело и немецкое название - Циммерталь - по фамилии его основателя. 
1907 года в село Протасово. «Сначала колонисты отправили ходока Исаака Фризена, который осмотрел земли, а потом уже поехали все остальные 125 семей. Имущество везли с собой. Государство обеспечивало бесплатный проезд с имуществом, скотом и инвентарем. Переселенцы получали ссуду 60 рублей на каждую семью. До Омска переселенцы ехали по железной дороге, а оттуда через Ильинку и Орлово на подводах в Протасово... Каждой семье при переселении давался надел 60 десятин, дробить который запрещалось. Его наследовал младший сын, а старшие были вынуждены наниматься в работники» (Смирнова, 2003, сс. 10-11).

Известны и другие примеры. Новосибирская область, Чистоозерный район, село Цветнополье: основано в 1906 г. лютеранами из Поволжья, затем сюда же приехали баптисты из Одессы. Старожилы вспоминают, что: «на каждую усадьбу давали 80 соток земли. Под пашню выделяли в среднем по 7 га земли» (с. 16). Омская область, католическое село Чучкино: «В Сибири землю получали наделами, на одну семью, по одном гектару на каждого мужчину. Первоначально жили все вместе, большими семьями, а потом, встав на ноги, молодые семьи отделялись, причем младший сын оставался с родителями и ухаживал за ними в старости. В деревне царили взаимопомощь, порядок и очень строгая дисциплина» (с. 20). Приведенные свидетельства информантов доказывают, что правило наследования родительского земельного надела было применимо ко всем конфессиональным группам немецкого населения и не зависело от вероисповедания.

Величина земельного надела определялась количеством имевшихся в регионе незанятых земель, а отнюдь не желанием переселенцев. Там, где природные и климатические условия были более благоприятными (юг Омской и Томской областей, Алтайский край), неосвоенных земель практически не оставалось. Северные таежные районы (Тарские урманы) либо засушливые солончаковые (Барабинская и Кулундинская степи) оставались малозаселенными, что и определяло в конечном счете размер земельного надела для переселенческой семьи. Характер же поселения во многом был предписан конфессиональными стереотипами.

Не все представители (и далеко не всех этносов!) одинаково хорошо ассимилировались с принимающим социумом. Об особенностях расселения в Сибири немцев католического вероисповедания мы писали ранее (Недзелюк, 2009, 2012, 2016). Бесконфликтный тип взаимодействия с принимающим социумом демонстрировали переселенцы, вливавшиеся в уже существовавшие сельские общества, а также не претендовавшие на «удобные» земли в полосе строительства 
железной дороги. Фронтирная этноконфессиональность становилась явной в тех случаях, когда новоселы претендовали на земельные участки, ранее занятые старожилами для выпаса скота либо пастбищ. С точки зрения чиновников Переселенческого управления, земли, не занятые непосредственно посевами, являлись «пустыми»; старожилое же население Сибири не считало малозаселенные и лесные территории неосвоенными. Степи использовались ими в качестве пастбищных угодий, таежные урманы - для лесных промыслов. Безусловно, плотность местного, в массе своей кочевого, населения здесь была ничтожной, но сам факт вторжения мигрантов расценивался ими как покушение на вековые устои. Как справедливо отметила Т.Н. Плохотнюк, «Переселенцы пытаются строить новое сообщество в незнакомой экологической обстановке. Преобразуя ландшафо, переселенцы меняются под воздействием самого ландшафта, выявляя свои возможности» (Плохотнюк, 2016, с. 95).

\section{Литургическая обрядность, праздники}

Визуальные свидетельства, дошедшие до наших дней благодаря музейным коллекциям и семейным архивам, позволяют реконструировать этнические и конфессиональные особенности быта сибирских немцев. Основная тематика семейных фотографий - национальные праздники и религиозные обряды. Свадьба и похороны, Рождество и Пасха, первое причастие и отпевание - вот перечень типичных поводов для фотографирования. Семейные фотоархивы немцев являются большой редкостью. За годы переселений и скитаний многое утрачено. То немногое, что уцелело, бережно хранилось и передавалось из поколения в поколение, от дедов к внукам. Примечательно, что фото дорогих и близких людей хранились в том же углу, что и иконы, за лампадой. Фотографии вкладывались в «метрики», сберегались между страниц тетрадок с рукописными молитвами. Нами обобщен опыт томских и новосибирских немцев (Крайслер, Дуквен, Целлер, Цигеман), приехавших в Новосибирскую область в 1950-е годы из Казахстана. Известен пример семейного фотоальбома Веры Гардер из Свердловской области:

«Фотографии были спрятаны в единственную книгу, которую удалось взять с собой. Это была Библия на немецком языке, на которую была надета обложка “Сказки А.С. Пушкина” (Киссер \& Смирнова, 2020).

Как подчеркивает Т. Н. Плохотнюк, «принцип религиозного субъективизма», помноженный на исключительный авторитет Библии как сакрального текста и усиленный посылом спасения личной верой, 


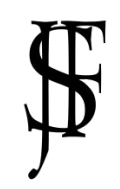

Журнал Фронтирных Исследований. 2021. No 4 | ISSN: 2500-0225

Этнические меньшинства в контактных зонах | Doi: https://doi.org/10.46539/jfs.v6i4.342

давали мощный импульс и католикам, и протестантам к выстраиванию замкнутого конфессионального социума (2017).

Как правило, на фотографиях запечатлены важные для семьи моменты свадьбы/венчания, конфирмации, похорон. Католические обряды совершались священнослужителем, который также попадал «в поле зрения» объектива. Участвовавшие в религиозном таинстве надевали специальную одежду. Протестанты более просты в обрядности: торжественных «парадных» фото у них гораздо меньше. Особенности фронтирной идентификации подчеркиваются представителями иных этносов, в том числе русского: «немецкая свадьба», «немецкие похороны», «немецкая Пасха».

Не только в период активных переселений, но и позже, в советские годы, исследователями отмечался важный феномен: «специфика ментальности вызывала, как правило, более негативную реакцию немцев на большевистские эксперименты и действия, более упорное сопротивление попыткам взломать традиционный образ жизни... характерным примером могут служить коллективизация и борьба с религией... Немецкие крестьяне яростно сопротивлялись им, хорошо понимая, что это конец многолетним основополагающим устоям их жизни» (Герман, 2019). Праздничная национальная немецкая обрядность вплоть до настоящего времени отличает представителей данной национальности от других, проживающих в тех же населенных пунктах. Примечательно, что и в католической, и в протестантской традициях Рождество и Пасха не совпадают в числах с православными, предшествуя им, а значит - каждый раз напоминая о самобытности традиций. Сегодня мононациональные поселки представляют собой большую редкость. Даже те национальные поселения, о которых мы упоминали в начале статьи, населены казахами, русскими, украинцами, белорусами (большинство немцев покинуло их, уехав в Германию).

Как видим, в вопросах обрядности, как праздничной, так и бытовой, наиболее значимым в ситуации сибирского фронтира оказался не конфессиональный, а этнический элемент.

\section{ЗАКЛЮЧЕНИЕ}

«Просим прислать нам священника нашей немецкой национальности...», - с такими словами обращались сто лет назад немцы католического вероисповедания поселков Келлеровка Акмолинской области и Мариенбург Томской губернии к Могилевскому римско-католическому митрополиту (РГИА, 1912, л. 14). В силу административно-территориальной специфики, католические приходы в Сибири принадле- 
жали не к Тираспольской епархии с центром в Саратове, а к Могилевской, с курией в Санкт-Петербурге.

В штате Могилевской епархии не было священнослужителей немецкой национальности, что раздражало келлеровцев и мариенбуржцев - переселенцев из Поволжья в Акмолинскую область и Томскую губернию Западной Сибири (РГИА, 1909-1911). Ни белорус, ни латыш, ни украинец не устроили прихожан. Их жалобы на конфликтный тип взаимоотношений с представителем клира основывались на незнании настоятелем немецкого языка. Объяснение, что большинство переселенцев, в первую очередь старики, женщины и дети, не знают никакого языка, кроме родного, немецкого, заслуживает внимания (Shaidurov, 2018). Контент-анализ обращений келлеровцев и мариенбуржцев в митрополитальную курию к католическому митрополиту демонстрирует частоту упоминаний терминов «Немец», «Немецкая национальность», «Немецкий язык». Примечательно, что во всех случаях перечисленные термины написаны с заглавной буквы.

На основании приведенных фактов и анализа работ историков, социологов, религиоведов мы пришли к ряду выводов. Концепция соотносительности конфессионального и этнического дискурсов не является универсальной и «не работает» одинаково применительно ко всем случаям, что наглядно демонстрирует феномен поликонфессиональности немецкого этноса в Сибири.

Для иноэтничного окружения в ситуации «сибирского фронтира» наиболее важным оказался фактор этнической идентификации, что подтверждается визуальными артефактами праздничной обрядности и зафиксированными материалами устной истории. Во взаимоотношениях хозяйственного, брачно-семейного характера на первое место ставился фактор религиозности, принадлежности к конкретной конфессиональной традиции.

Наши выводы подтверждаются результатами, полученными С. В. Курске и Т. Б. Смирновой в ходе проведенного ими всероссийского опроса. Немецкий язык респондентами отмечался как маркер идентичности, в том числе «множественной идентичности» в случае имевших место поликонфессиональных браков. И наоборот, значительным числом респондентов (выборка из 1500 человек) религия была выделена в качестве основного мотива для выбора национальности (в случае множественной идентичности) (Курске \& Смирнова, 2011). 


\section{Список литературы}

Beliakova, N., \& Dobson, M. (2016). Protestant women in the late Soviet era: Gender, authority, and dissent. Canadian Slavonic Papers, 58 (2), 117-140. doi: $10.1080 / 00085006.2016 .1157923$

Forbes, J. D. (1968). Frontiers in American History and the Role of the Frontier Historian. Ethnohistory, 15 (2), 203. doi: 10.2307/480 557

Shaidurov, V. N. (2018). The German catholic community of Marienburg from the end of the 19th till the beginning of the 20th century: Some aspects of the local history. Rusin, 2 (52), 288-308. doi: 10.17223/18572685/52/20

Беглов, А., Токарева, Е., \& Фадеев, И. (2020). Литургические практики католиков Советской России в 1920-1930-е гг.: Нормы и аномалии. Государство, религия, Церковь в России и за рубежом, 38 (4), 265-293.

Белякова, Н., \& Микешин, И. (2018). Гендерные стратегии и дисциплинарные практики в религиозных сообществах. Государство, религия, Церковь в России и за рубежом, 36 (2), 7-16.

Бетхер, А. Р. (2004). Особенности развития хозяйства у различных локальных групп немецкого населения Западной Сибири в конце XIX - начале XX в.

В Ключевые проблемы истории российских немщев (сс. 274-290). Москва: Готика.

Вибе, П. П. (2017). Ментальность и поведенческие практики немецких колонистов как факторы формирования их адаптационных и колонизационных возможностей: На примере немецких колоний Омского уезда (конец XIX - первая треть XX вв.). Лютеране в России: к 500-летию Реформащии, 13-20. Омск: Омский государственный технический университет.

Герман, А. А. (2019). Национальная идентичность российских немцев под прессом большевизма. Проблемы российской цивилизации и методики преподавания истории, (11), 83-94.

Глинка, Г. В. (2014). Азиатская Россия. Том 1. Люди и порядки за Уралом. Санкт-Петербург: Переселенческое управление.

Кузнецов, В. К. (1912). Сборник статистических сведений об экономическом положении переселенцев в Сибири: Материалы по обследованию типичных переселенческих поселков. Выпуск 1-5. Санкт-Петербург: Переселенческое управление.

Курске, В. С., \& Смирнова, Т. Б. (2011). Этническая идентичность российских немцев в начале XXI в. (По результатам всероссийского опроса). Журнал социологии и социальной антропологии, 14 (1), 160-177.

Лиценбергер, О. А. (2014). Миграция и этнические стереотипы (по материалам социологического исследования в Саратовской области). Вестник Поволжской академии государственной службы, (4), 70-78.

Нагнибеда, В. Я. (Ред.). (1913). Сборник статистических сведения об экономическом положении переселенцев в Томской губернии. Уездь Барнаульский, Каинский, Томский и Мариинский. Выпуск 1. Томск: Типография В. М. Перельман. 
Недзелюк, Т. Г. (2009). Римско-католическая церковь в полиэтническом пространстве Западной Сибири. 1881-1918 г2. Новосибирск: Прометей.

Недзелюк, Т. Г. (2012). Информационное пространство Сибири в картине мира западных мигрантов-аграриев. Первые Ядринцевские чтения, 66-68. Омск: Омский историко-краеведческий музей.

Недзелюк, Т. Г. (2016). Конфессиональное сообщество католиков Сибири: Влияние мировоззрения на повседневную жизнь (1830-1917 г2.). Новосибирск: Издательство Сибирского института государственной службы.

Панарина, Д. С. (2015). Граница и фронтир как фактор развития региона и/или страны. История и современность, (1), 15-41.

Плохотнюк, Т. Н. (2016). Российские немцы в условиях северокавказского фронтира XIX в.: Проблемы природно-хозяйственной адаптации. Образование, жизнь и судьба немецких поселений в России, 86-96. Маркс: РусДойчМедиа.

Плохотнюк, Т. Н. (2017). Протестантизм и миграция: Религиозный фактор переселения немцев на Северный Кавказ. Гуманитарные и юридические исследования, (2), 116-122.

Резун, Д. Я., \& Шиловский, М. В. (2005). Сибирь, конец XVI - начало ХХ вв.: Фронтир в контексте этносоциальных и этнокультурных процессов. Новосибирск: Сова.

Ремнев, А. В. (2011). Национальность «сибиряк»: Региональная идентичность и исторический конструктивизм XIX в. Полития: Анализ. Хроника. Прогноз (Журнал политической философии и социологии политики), (3), 109-128.

Ремнев, А. В. (2015). Сибирв в имперской географии власти XIX-начала ХХ веков. Омск: Омский государственный университет.

Российский государственный исторический архив. (1909-1911). Ф. 826. On. 1. Д. 1825.

Российский государственный исторический архив. (1912). Ф. 826. Оn. 1. Д. 1859.

Смирнова, Т. Б. (2002). Немщь Сибири: Этнические процессы. Новосибирск: Русинко.

Смирнова, Т. Б., \& Киссер, Т. С. (2020). Этничность российских немцев в фотографиях: Видимые образы и скрытые смыслы. Уральский исторический вестник, (3), 45-54. doi: 10.30759/1728-9718-2020-3(68)-45-54

Юрасов, И. А., \& Юрасова, О.Н.(2020). Конфессиональная и религиозная идентичности: Этнос, дискурс. Религиоведение, (4), 108-118. doi: 10.22250/20728662.2020.4.108-118

\section{References}

Beglov, A., Tokareva, E., \& Fadeev, I. (2020). Liturgical Practices of Catholics in Soviet Russia in the 1920s and 1930s: Norms and Anomalies. Government, Religion, and Church in Russia and Abroad, 38 (4), 265-293. (In Russian). 
Beliakova, N., \& Dobson, M. (2016). Protestant women in the late Soviet era: Gender, authority, and dissent. Canadian Slavonic Papers, 58 (2), 117-140. doi: 10.1080/00 085 006.2016.1157923

Belyakova, N., \& Mikeshin, I. (2018). Gender Strategies and Disciplinary Practices in Religious Communities. Government, Religion, and Church in Russia and Abroad, 36 (2), 7-16. (In Russian).

Betcher, A. R. (2004). Peculiarities of economic development of different local groups of the German population of Western Siberia in the late 19th-early 20th century. In Key problems of the history of Russian Germans (pp. 274-290). Moscow: Gothic. (In Russian).

Forbes, J. D. (1968). Frontiers in American History and the Role of the Frontier Historian. Ethnohistory, 15 (2), 203. doi: 10.2307/480 557

Glinka, G. V. (2014). Asian Russia. Volume 1. People and Orders Beyond the Urals. St. Petersburg: Resettlement Department. (In Russian).

Herman, A. A. (2019). The National Identity of Russian Germans under the Pressure of Bolshevism. Problems of Russian Civilization and History Teaching Methodology, (11), 83-94. (In Russian).

Kurske, V. S., \& Smirnova, T. B. (2011). The Ethnic Identity of Russian Germans in the Beginning of the 21st Century. (According to the results of the All-Russian survey). Journal of Sociology and Social Anthropology, 14 (1), 160-177. (In Russian).

Kuznetsov, V. K. (1912). Collection of statistical data on the economic situation of migrants in Siberia: Materials on the survey of typical migrant settlements. Issue 1-5. St. Petersburg: Resettlement Department. (In Russian).

Licenberger, O. A. (2014). Migration and Ethnic Stereotypes (Based on Sociological Research in the Saratov Region). Bulletin of the Volga Region Academy of Public Service, (4), 70-78. (In Russian).

Nagnibeda, V. Y. (Ed.). (1913). Collection of statistical data on the economic situation of migrants in Tomsk Province. Barnaul, Kainsk, Tomsk and Mariinsk uyezds. Issue 1. Tomsk: Printing house of V.M. Perelman. (In Russian).

Nedzeluk, T. G. (2009). The Roman Catholic Church in the Multi-ethnic Space of Western Siberia. 1881-1918. Novosibirsk: Prometheus. (In Russian).

Nedzeluk, T. G. (2012). The Information Space of Siberia in the World Picture of Western Migrant Agrarians. First Yadrintsev Readings, 66-68. Omsk: Omsk Museum of History and Regional Studies. (In Russian).

Nedzeluk, T. G. (2016). The Confessional Community of Catholics in Siberia: The Influence of Worldview on Everyday Life (1830-1917). Novosibirsk: Publishing house of the Siberian Institute of Public Service. (In Russian).

Panarina, D. S. (2015). The Border and the Frontier as a Factor in the Development of a Region and/or a Country. History and Modernity, (1), 15-41. (In Russian).

Plokhotnyuk, T. N. (2016). Russian Germans in the North Caucasus Frontier in the 19th Century: Problems of Natural and Economic Adaptation. Education, life, and the fate of German settlements in Russia, 86-96. Marx: RusDouchMedia. (In Russian). 
Plokhotnyuk, T. N. (2017). Protestantism and Migration: The Religious Factor of German Resettlement in the North Caucasus. Humanities and Law Studies, (2), 116-122. (In Russian).

Remnev, A. V. (2011). Nationality "Siberian": Regional Identity and Historical Constructivism in the 19th Century. Politia: Analysis. Chronicle. Forecast (Fournal of Political Philosophy and Sociology of Politics), (3), 109-128. (In Russian).

Remnev, A. V. (2015). Siberia in the imperial geography of power in the 19th and early 20th centuries. Omsk: Omsk State University. (In Russian).

Rezun, D. Y., \& Shilovsky, M. V. (2005). Siberia, late 16th - early 20th centuries: Frontier in the context of ethno-social and ethno-cultural processes. Novosibirsk: Sova. (In Russian).

Russian State Historical Archive. (1909-1911). F. 826. In. 1. C. 1825. (In Russian).

Russian State Historical Archive. (1912). F. 826. In. 1. C. 1859. (In Russian).

Shaidurov, V. N. (2018). The German catholic community of Marienburg from the end of the 19th till the beginning of the 20th century: Some aspects of the local history. Rusin, 2 (52), 288-308. doi: 10.17223/18572685/52/20

Smirnova, T. B. (2002). The Germans of Siberia: Ethnic Processes. Novosibirsk: Rusinko. (In Russian).

Smirnova, T. B., \& Kisser, T. S. (2020). Ethnicity of Russian Germans in Photographs: Visible Images and Hidden Meanings. Ural Historical Bulletin, (3), 45-54. doi: 10.30759/17289718-2020-3(68)-45-54 (In Russian).

Vibe, P. P. (2017). Mentality and behavioral practices of German colonists as factors in the formation of their adaptation and colonization capabilities: The example of the German colonies in Omsk County (late 19th century - first third of the 20th century). Lutherans in Russia: On the 500th Anniversary of the Reformation, 13-20. Omsk: Omsk State Technical University. (In Russian).

Yurasov, I. A., \& Yurasova, O. N. (2020). Confessional and Religious Identities: Ethnos, Discourse. Religious Studies, (4), 108-118. doi: 10.22250/2072-8662.2020.4.108-118 (In Russian). 